\title{
Planificación urbana-regional y paisaje: impronta de los planes 1960-1994 para Santiago de Chile
}

\author{
M. Isabel Pavez R.
}

\section{Filiación}

Académica del Departamento de urbanismo de la F.A.U. de la Universidad de Chile.

\section{Resumen}

Se indaga en el potencial paisajístico del espacio intersticial público incorporado en los planes de ordenamiento territorial para la Región e Intercomuna de Santiago, aprobados técnicamente en 1958 y oficialmente desde 1960, dando la capacidad de soporte fundamental para la transformación de la ciudad tradicional de Santiago en una Metrópoli.

Palabras claves: Planificación urbana, planificación regional, paisaje, Santiago de Chile.

\begin{abstract}
This reflection is referred to the landscaping potential of the interceding public space incorporated into the territorial regulatory plans for the Region and for inter-local authority coordination. These were technically approved in 1958 and officially in 1960, giving the capacity for a fundamental support for the transformation of the traditional city of Santiago into a metropolis.
\end{abstract}

\section{Key words}

Urban planning, regional planning, landscape, Santiago de Chile.

\section{Sumario}

Introducción

1.-Concepción paisajística global

1.1.- Sobre incremento de superficies

1.2.-Sobre incremento de la diversidad en el espacio público

1.3.-Sobre integración del medio natural y el medio artificial

1.4.-Sobre instauración de circuitos y espacio público

1.5.-Sobre el incremento de bienes de uso público

2. Influencia de los altos inspiradores

2.1.-Sobre espacio habitable como una totalidad sistémica

2.2.-Sobre estudios multidisciplinarios previos

2.3.-Sobre directrices de planeamiento e implementación día a día

2.4.-Sobre diversificación de la oferta de espacios públicos

2.5.- Sobre elevación de la densidad de población en medio urbano

2.6.-Sobre el espacio regional como un espacio de interés también paisajístico y disfrute colectivo

3. Conclusión 


\section{Introducción}

Pensamos que los planes de ordenamiento territorial para la Región e Intercomuna de Santiago aprobados oficialmente en $1960^{1}$, sustentaron una concepción paisajística global para una región metropolitana, integrando proposiciones de espacios verdes y viales en el nivel estructurante, con una visión sistémica, coordinando las escalas regionales, microregionales, intercomunales y comunales.

La formación de los autores de estos planes ${ }^{2}$ en la, entonces, "Facultad de Arquitectura" de la Universidad de Chile, entre 1947 y 1952 y, posteriormente, en otras instituciones en el extranjero, estaría sugiriendo al menos ${ }^{3}$, una fuerte influencia en sus proyectos especialmente de las escuelas de Sir Patrick Geddes (1854-1932), Lewis Munford (1895-1990), de los arquitectos Robert Auzelle (1913-1983), Gaston Bardet (1907-1989), y el precursor chileno Luis Muñoz Maluschka (1896-1974) en las materias de interés.

Asumiendo que la definición de los espacios públicos se realiza en tres momentos, a saber:

- el planeamiento, con la concepción de los sistemas de espacios públicos para el cumplimiento de diversas funciones (áreas verdes, áreas duras, vías) donde se establece caracterización funcional, su jerarquización, la forma de distribución, su localización, y su dimensionamiento,

- el diseño del polígono instaurado como espacio intersticial público, con la concepción de su trazado en planta, la selección y distribución de sus componentes, y

\footnotetext{
${ }^{1}$ Nos referimos a los proyectos originales expresados en los siguientes planos y memorias oficiales:

Proyecto: CHILE - MINISTERIO DE OBRAS PUBLICAS, Dirección de Arquitectura, Departamento de Urbanismo y Vivienda, Sección Planes Intercomunales, "PLANO MICROREGIONAL - REGION IV-B SANTIAGO DE CHILE". Firmado por Director Arqto. Edwin Weil W.; Jefe Depto. Arqto. Juan Honold D.; Jefe Plan Intercomunal Urbanista Arqto. Juan Parrochia B. (F-P; 96 × 76 cm; inscripción N²5567), escala gráfica. Reducción de escala original 1:100.000; impreso en colores, Instituto Geográfico Militar, Santiago de Chile, s/f (1960). Es colección de planos. /

Proyecto: CHILE - MINISTERIO DE OBRAS PUBLICAS, Dirección de Planeamiento, Departamento de Planos Reguladores, "PLANO INTERCOMUNAL DE SANTIAGO", firmado por Director Ing. Jorge Kelemen; Jefe Departamento Arqto.Osvaldo Hufe; Jefe Plan Intercomunal Arqto. Juan Honold; Urbanista Arqto. Juan Parrochia, (Colección de planos de 77 x $55 \mathrm{~cm}$.; Escala Gráfica, (escala original 1:20.000), impresión en colores en su mayoría sobre plano base blanco y negro, 1958, Instituto Geográfico Militar. /

Memoria: CHILE - DIARIO OFICIAL DE LA REPUBLICA DE CHILE, N²4.829, de 27 de diciembre de 1960, "Ministerio de Obras Públicas aprueba Plan Intercomunal de Santiago y la Ordenanza respectiva", pp. 2.4272.432.

2 CHILE - MINISTERIO DE OBRAS PÚBLICAS, Dirección de Planeamiento, Departamento de Planos Reguladores, Director Ing. Jorge Kelemen; Jefe Departamento Arqto.Osvaldo Hufe; Jefe Plan Intercomunal Arqto. Juan Honold; Urbanista Arqto. Juan Parrochia (Primer Director del Plan, desde su aprobación en 1960).

${ }^{3}$ Debe considerarse que la influencia de los grandes proyectos precedentes, como el Plan de Londres, o la influencia de la A.R.L. de Hannover a través de L. Muñoz Maluschka, se hacen presentes entre varias otras improntas, pero por razones de espacio y objetivos no se abordan en este escrito.
} 
- la regulación de los predios del entorno, materia frecuentemente olvidada ${ }^{4}$,

nos proponemos observar el potencial paisajístico en los proyectos aprobados desde 1960 , en lo que corresponde a la acción de planeamiento. Los capítulos referidos al diseño de los polígonos y regulación de sus entornos han sido responsabilidad de las específicas comunas beneficiadas con la colaboración del ministerio público correspondiente, y no son tratados en este escrito.

Estimamos que el potencial paisajístico en los planes de interés se constatará toda vez que, en la intercomuna y micro-región de la metrópolis proyectada de Santiago, los planes hubieran:

- a) incrementado significativamente la superficie de espacio intersticial de interés público -proporcionando los estándares que corresponden a una ciudad de status metropolitano- a partir de lo cual se favorece el desarrollo de las actividades recreativas en un marco morfológico-paisajístico y funcional adecuado a la magnitud de las necesidades, y también el desarrollo de las comunicaciones en el territorio;

- b) diversificado los roles del espacio intersticial público -y con ello, abierto la posibilidad de enriquecer la expresión paisajística del medio habitado- conforme corresponde a la mayor complejidad de funciones propia de una ciudad metrópolis llamada a servir no sólo las necesidades internas, sino también del área de impacto o región urbana, sin olvidar las relaciones nacionales e internacionales;

- c) integrado elementos estructurantes del medio natural con los elementos estructurantes del medio proyectado;

- d) generado circuitos ligando los polígonos intersticiales públicos tanto al interior del medio urbano, como entre medio urbano y medio rural, de tal forma de favorecer la percepción y legibilidad de los sistemas paisajísticos urbanos y rurales en desarrollo en las diversas escalas;

- e) establecido legalmente la patrimonialidad pública a las áreas proyectadas o confirmadas, manifestando con ello la voluntad de resguardo a través del tiempo de estos bienes públicos y sus valores múltiples, incluido el valor paisajístico.

Estas medidas, habrían favorecido la focalización y/o captura de las presencias del macro-paisaje, habrían abierto la posibilidad de enriquecer el paisaje intermedio mediante diseños seccionales posteriores en manos de diversos otros autores, y habrían potenciado la posibilidad de definición de un micro-paisaje local en todas las funciones del espacio público: vías, paseos, parques y otros, incrementando también por esto la participación de nuevos autores, y asegurando de esta forma una mayor riqueza en el resultado final.

4 ESPAÑA - MINISTERIO DE OBRAS PUBLICAS, Instituto del Territorio y Urbanismo, Espacios públicos urbanos. Trazado, Urbanización y Mantenimiento, José MARTÍNEZ S.; María A. HERRERO M; María MEDINA MURO, 1990, vid. pp.159-162. 


\section{Concepción paisajística global}

\subsection{Sobre incremento de superficies}

Santiago pre-metropolitana ocupaba en 1930 una superficie de $65 \mathrm{Km} .^{2},-6.500$ Hás. con una población de 696.000 habitantes; y disponía de diversos espacios verdes: el parque Cousiño (hoy parque O'Higgins), la Quinta Normal, el cerro Santa Lucía, el parque Gran Bretaña, numerosas plazas y, además, el Club Hípico, el Hipódromo Chile y diversas áreas deportivas. Los espacios verdes sumaban 800 Hás., eran el 12\% del área urbana, y representaban más de $11 \mathrm{~m}^{2}$ por habitante ${ }^{5}$.

En los Planes de Santiago aplicados desde 1960, se reservaron 4.000 hectáreas de áreas verdes urbanas y suburbanas - sin contar las áreas verdes rurales- para una población proyectada de 5.500.000 a 6.000.000 de habitantes para el año 2000 en un área urbana de 40.000 Hás. Se programó un aumento de la densidad bruta para alcanzar 100-150 hab/Hás., y la cifra de $7 \mathrm{~m}^{2}$ de áreas verdes públicas por habitante, esto es un $10 \%$ del área urbana total.

Los planes, propusieron el crecimiento del Gran Santiago mediante varios tipos de acción:

- renovación, rehabilitación y remodelación, contemplando mayores densidades dentro de ciertos márgenes establecidos;

- relleno de áreas eriazas al interior de la ciudad, y

- satelización sobre entidades antiguas o nuevas.

Se programó un sistema de satélites distribuidos dentro de la región metropolitana, en radios de 15, 30 y $45 \mathrm{~km}$ de distancia del núcleo principal, comprendiendo satélites residenciales, agrícolas, industriales y de recreación, con diversos grados de comunicación y autonomía.

Estas formas de crecimiento concebidas operando simultánea y coordinadamente a través del tiempo, tuvieron entre otros objetivos con efectos en el paisaje: prevenir la contaminación atmosférica creando núcleos industriales especializados y descentralizados en la región, en algunas de las ciudades satélites referidas; prevenir la especulación del suelo, creando núcleos urbanos con un rol claro, de buen nivel y calidad de vida para aumentar la oferta de terrenos adecuados para todos los estratos, para el comercio, la industria y el esparcimiento dentro de la región; producir un borde especial de transición y contacto entre áreas urbanas y rurales, por la creación de zonas suburbanas.

\footnotetext{
${ }^{5}$ PARROCHIA BEGUIN, Juan "La falta de áreas verdes y el incumplimiento de la ley". Conferencia, dictada en la II Bienal de Arquitectura de Santiago "Hacer Ciudad", el 18 de Agosto de 1979. Palacio Nacional de Bellas Artes, en: PARROCHIA, Juan (autor); PAVEZ, M. Isabel (compiladora), El futuro de ayer y el futuro de hoy, Departamento de Urbanismo, F.A.U. U. de Chile, 180 págs., 1987.
} 
Así, Santiago Intercomunal debió contar en 1979, con una superficie de espacios verdes equivalente, como mínimo, al $7 \%$ del área urbanizada a partir de 1930. Esta superficie de 2.352 Hás., sumada a las existentes 800 Hás., daría en 1979, 3.152 Hás. de áreas verdes como Bien Nacional de Uso Público. Esto habría significado casi $8 \mathrm{~m}^{2}$ por cada habitante, representando un $8 \%$ del suelo urbano ${ }^{6}$.

En lo referido a espacios públicos viales, se observa que desde la creación, en 1965, de los servicios de Vialidad Urbana y Metro en el M.O.P., y hasta 1975, se construyeron del orden de $80.000 \mathrm{~m}^{2}$ de estaciones de Metro; $100.000 \mathrm{~m}^{2}$ de túneles; $3.500 .000 \mathrm{~m}^{2}$ de pavimento, y 3.000 metros lineales de puentes (ancho tipo $7 \mathrm{~m}$.) para la metrópolis de Santiago. Estas obras constituyeron avances sobre los proyectos y anteproyectos desarrollados para efectos de $3.000 \mathrm{Km}$. de calles y avenidas, y $100 \mathrm{Km}$. de líneas de Metro, las que quedaron expresadas en más de 50.000 planos $^{7}$.

Cabe destacar que al momento de anunciarse la Política de Desarrollo Urbano de 1979, los continuadores de la realización del Plan en las diversas instancias y escalas, no habían logrado sobrepasar las 1.000 Hás. de áreas verdes realmente de uso público mínimamente habilitadas. Santiago sólo contaba en 1979 con un poco más de lo que se tenía en 1930.

La Política Nacional de Desarrollo Urbano aplicada desde 1979, cambió la tendencia histórica, con la paulatina pérdida de las medidas de planificación para el ordenamiento territorial, y con un proceso de paulatino deconstructivismo en lo referido al patrimonio de áreas públicas en especial verdes, con el correspondiente impacto en el paisaje urbano y regional.

Esto ocurría en Chile, en el momento en que en Europa, a partir de 1980, se inició un trabajo sostenido de recuperación y creación de espacios públicos, tanto para su utilización diurna como nocturna ${ }^{8}$. Esta acción pasó a convertirse en el motor de la rehabilitación de las ciudades europeas.

Al presentarse en 1979, la nueva la Política Nacional de Desarrollo Urbano (Gobierno del Gral. A. Pinochet), el urbanista Juan Parrochia Beguin ${ }^{9}$, coautor de los Planes, señaló:

"Ni las autoridades públicas ni los profesionales se interesan realmente por las Areas Verdes, y ellas no forman parte de sus objetivos para el saneamiento ambiental y,

\footnotetext{
${ }^{6}$ PARROCHIA B., Juan (autor y co-autor de contenidos), PAVEZ REYES, M. Isabel (compiladora), El Plan Tridimensional de Ordenamiento Territorial y la Región Metropolitana de Santiago 1960-2000, Edición del Departamento de Urbanismo, F. A.U., U. Chile, 216 págs. ilustradas, Santiago, 1994.

7 PAVEZ REYES, M. Isabel, En la Ruta de Juan Parrochia Beguin. Premio Nacional de Urbanismo - Chile 1996, Departamento de Urbanismo de la F.A.U. de la Universidad de Chile, producido en 1998-1999, 308 páginas, 465 ilustraciones, libro inédito.

${ }^{8}$ Véase al respecto, O'CONNOR, Justin, 1997, "Donner de l'espace public à la nuit: le cas des centres urbains en Grande- Bretagne", en Les Annales de la Recherche Urbaine N०77, pp.40-46.

9 PARROCHIA BEGUIN, Juan 1979, op.cit.

Revista de Urbanismo $\mathrm{N}^{\circ} 6$ - Julio de 2002 
Planificación urbana-regional y paisaje: impronta de los planes 1960-1994 para Santiago de Chile

aparentemente, son lujos ajenos a su quehacer o sólo temas de moda para sus charlas, cursos o artículos. El poder privado ve en las Areas Verdes un impuesto más a sus negocios, y su astucia consiste en esquivarlas. La población no exige a las autoridades, ni a la oferta del poder privado, las Areas Verdes necesarias para la protección del Medio Ambiente y el equilibrado desenvolvimiento de su vida y la de sus hijos. Con diversos grados de culpa, hay una grave responsabilidad de los adultos de este país, en la destrucción de la calidad de vida de la población, en lo que se refiere a Areas Verdes y contaminación ambiental. Ningún acto, medida efectista, declaración, discurso, homenaje, escrito, etc., podrá ser suficiente para esconder y disimular dicha responsabilidad y dicha culpa. Sin embargo, la responsabilidad de lo que está acaeciendo no puede quedar escondida en el anonimato, diciendo que todos son culpables y que ello ha sucedido por ignorancia, a través de un largo período. La culpa debe ser investigada para el conocimiento de la población, para la vergüenza de sus autores, para evitar que el delito se repita y, en último caso, para disimular la ignorancia. Sólo una acción diaria, sistemática, permanente y prolongada, con hechos y obras podrá, algún día, demostrar que realmente existe una verdadera preocupación por la protección ambiental de nuestra ciudad".

En el año 2000, las áreas verdes de Santiago sumaron 3.000 Hás., pero sólo 1.000 se mantenían forestadas. Se contó en este año con $2,5 \mathrm{~m}^{2}$ de parques construidos por habitante, las normas internacionales recomiendan $9 \mathrm{~m}^{2}{ }^{10}$, los planes de 1960 previeron espacio para $7 \mathrm{~m}^{2}$ por habitante.

\subsection{Sobre incremento de la diversidad en el espacio público}

Los planes de 1960 diversificaron los tipos de espacio intersticial público, superando la aplicación de los conceptos de "plaza de armas", "plaza de barrio", "alameda", "paseo de tajamares", "parque", "cancha de carrera de caballos", "campo de Marte", "estadio", "hipódromo", y algún otro, considerado hasta ese momento. Se enriqueció en sus proposiciones la primaria clasificación de roles y jerarquías de vías que había definido Karl Brunner en el Plan de Santiago de 1934/3911.

\footnotetext{
10 DELPIANO, Ramón, Director Nacional Colegio de Arquitectos de Chile, "Venta de Areas Verdes", en Sección Opinión, El Mercurio, Santiago, 22 de junio de 2000, p. A2.

${ }^{11}$ Cabe recordar que el principal problema que Brunner observaba era el de la accesibilidad a la ciudad. Sus proposiciones de micro-urbanismo para efectos de liberar el centro de las manzanas, por ejemplo, tenían no sólo un objetivo de crear espacios verdes vecinales, sino también ofrecer lugares para estacionamiento de vehículos, pues las vías de perfil colonial heredadas no podrían asumir el volumen creciente de vehículos en circulación y con necesidades de estacionar en el espacio público.
} 


\title{
DIVERSIDAD DE ESPACIOS VERDES
}

En los Planes de 1960, y en su posterior aplicación, se abordó un sistema coordinado de espacios verdes de uso público, destinados al esparcimiento de la población y al saneamiento ambiental. En ellos no se podría ejecutar construcciones de ninguna naturaleza, salvo aquellas destinadas a complementar las funciones de esos espacios verdes como tales.

Se incorporó los siguientes conceptos y reservas:

Reservas Forestales Rurales: áreas rurales inmediatas a la ciudad, destinadas a plantaciones de árboles y matorrales que se adaptaran a las condiciones naturales del terreno:

\begin{abstract}
Reserva Forestal Oriente: una faja entre las cotas 900 y 1.000 de la precordillera de Los Andes, abarcando desde Las Condes, por el norte, hastalos Cerros de La Puntilla de Pirque, por el sur;

Reserva Forestal Norte: el Cerro Manquehue y otros cerros vecinos señalados en el Plano de Zonificación; Reserva Forestal Poniente: la cuenca del Río Mapocho, desde el Estero de Lampa y los faldeos de los Cerros Amapola, Lo Aguirre, Bandera, Puntilla de los Vientos, Cerro Ratones, y el área de morrenas de Lo Prado Abajo;

Reserva Forestal Sur: Ios Cerros de Chena, Cerro Negro y Cerro Las Cabras en los Bajos de Mena, y otros.
\end{abstract}

Reservas Agrícolas y Forestales Suburbanas: terrenos agrícolas y ganaderos que debían conservar la utilización que presentaban en la época, y áreas destinadas a reservas forestales (distribuidas en superficies de 300 a 800 hectáreas):

Zona Quilicura - Renca - Barrancas, Zona Barrancas - Maipú, Zona San Bernardo, Zona La Granja, Zona Puente Alto, Zona Ñuñoa - La Reina, Zona Apoquindo - Las Condes, Zona cerro Alvarado, Zona Manquehue - San Cristóbal.

Cabe recordar al respecto, las apreciaciones que hacía Oscar Prager a comienzos de los años 1950, en su artículo "El arte del paisaje"12:

"Paisajes, resultado de una agricultura floreciente, pueden causar un placer estético mayor al que produce un trozo de la naturaleza, puesto que este placer no depende del objeto mismo sino de las leyes estéticas y su aplicación. La estructura de una ciudad, de una aldea, de una casa de campo, de una finca, de una fábrica, de un dique, de un ferrocarril, de un puente, puede satisfacer simultáneamente lo necesario y lo estético y debe unirse y vibrar con el ritmo del paisaje".

Parques Intercomunales (polígonos): espacios verdes y otros destinados a reuniones juegos, deportes, y otros; distribuidas en cada cuadrante urbano, con superficies entre 30 y 100 hectáreas. Sirven a las poblaciones de amplios sectores de

12 PRAGER, Oscar, "El arte del Paisaje", en: Anales de la Universidad de Chile. Memorias Científicas y Literarias, U. de Chile, primer trimestre de 1954, N॰93, pp.81-86. Se reproduce en Sección "Memoria Histórica" en el presente número de Revista de Urbanismo.

Revista de Urbanismo $N^{\circ} 6$ - Julio de 2002 
la ciudad, inclusive dos o más comunas, y que, en ocasión de exposiciones, fiestas tradicionales, etc., cuentan con afluencia de personas de toda el área metropolitana. Ellas fueron ${ }^{13}$ :

Comuna de Conchalí: Sector Avenida Dorsal, con 44 Hás. aprox.; Comuna de Quinta Normal, área de 52 Hás., aprox.; Comuna de Santiago: Parque Cousiño, con 140 Hás. aprox.; Comuna de Santiago: Quinta Normal, con 100 Hás. aprox.; Comuna de San Miguel: Sector Ochagavía, con 36 Hás. aprox.; Comuna de San Miguel: Est. La Castrina, con 104 Hás. aprox.; Comuna de Ñuñoa: Country Club, con 60 Hás. aprox.; Comunas de Santiago - Conchalí - Las Condes: Cerro San Cristóbal, con 252 Hás. aprox.; Comuna de Las Condes: Club de Golf, con 64 Hás. aprox.

\title{
Parques Intercomunales (cuencas de Ríos):
}

Cuenca del Río Mapocho, con una superficie aproximada de 690 Hás.

Cuenca del Río Maipo, frente a Puente Alto, con una superficie aproximada de 30 Hás.

Parques Comunales: con una extensión que fluctúa entre 8 y 15 Hás., aprox. Sirven especialmente a una comuna 0 a determinados barrios de la misma. Sus características son similares a los Parques Intercomunales, pero su zona de influencia es más reducida. Se emplazan junto a barrios populosos, aprovechando sitios eriazos, además de confirmar el destino de varios parques existentes.

Se establecieron las siguientes áreas ${ }^{14}$, (denominación y división político-administrativa vigente en 1958):

\begin{abstract}
Comuna de Conchalí: Dorsal - El Salto, 11 Hás. aprox.; Comuna de Santiago: Cerro Blanco, 18 Hás. aprox.; Comuna de Conchalí:Independencia, 12 Hás. aprox.; Comuna de Conchalí: Dgo. Santa María, 8 Hás. aprox.; Comuna de Quilicura: área de 8 Hás. aprox.; Comuna de Renca: área de 14 Hás. aprox.; Comuna de Quinta Normal: Parque Lo Franco, 4 Hás.; Comuna de Quinta Normal: Cerro Navia, 8 Hás. aprox.; Comuna de Quinta Normal: Estadio Municipal, 4 Hás.; Comuna de Santiago: Cerro Santa Lucía, 5 Hás. aprox.; Comuna de Santiago: Sector San Pablo, 10 Hás. aprox.; Comuna de Santiago: La Palma, 12 Hás. aprox.; Comuna de Santiago: San Joaquín, 10 Hás. aprox.; Comuna de Santiago: Sector Avda. Matta Sur, 8 Hás.; Comuna de Santiago: Sector 10 de Julio, 8 Hás.; Comuna de Barrancas: área de 12 Hás. aprox.; Comuna de La Cisterna: área de 10 Hás. aprox.; Comuna de La Cisterna: Lo Valledor Sur,10 Hás.; Comuna de La Cisterna: La Blanca,16 Hás. aprox.; Comuna de La Cisterna: Avda. Progreso,12 Hás.; Comuna de San Bernardo: área de 8 Hás.; Comuna de San Miguel: La Feria, 8 Hás.; Comuna de San Miguel: Ciudad del Niño, 10 Hás.; Comuna de San Miguel: La Legua, 12 Hás.; Comuna de La Granja: área de 8 Hás.; Comuna de La Florida: área de 10 Hás.; Comuna de La Florida: Las Mercedes, 10 Hás.; Comuna de Puente Alto: área de 8 Hás.; Comuna de Ñuñoa: Simón Bolívar, 10 Hás.; Comuna de Ñuñoa: Santa Julia, 14 Hás.; Comuna de Ñuñoa: Escuela Agrícola, 12 Hás.; Comuna de Providencia: Antonio Varas, 16 Hás.; Comuna de Las Condes: Lo Saldes, 16 Hás.; Comuna de Maipú: área de 12 Hás.;
\end{abstract}

13 Denominación y división político-administrativa vigente en 1958.

${ }^{14}$ Denominación y división político-administrativa vigente en 1958.

Revista de Urbanismo Nº6 - Julio de 2002 
Áreas Especiales: áreas verdes existentes de propiedad pública o privada, de uso controlado o restringido:

- Areas Deportivas: Estadio Nacional, Club Hípico, Hipódromo, Estadio Colo-Colo, etc.

- Parques Privados: Parque Macul, Lo Hermida, Balneario Apoquindo, etc.

\section{Áreas de Interés Histórico y Cultural:}

- Convento Los Dominicos, en Apoquindo; Iglesia y Gruta de Lourdes, etc.

La voluntad de hacer sustentable el asentamiento humano fue evidente en los planes, toda vez que se dispuso medidas para la protección de todos los recursos agrícolas de la región, evitando su destrucción por crecimiento urbano; para la recuperación de los ámbitos ecológicos de la vida silvestre en todos los cerros, montañas y mares de la región; para la reforestación de los terrenos de baja calidad agrícola cuyos bosques habían sido destruidos con el consumo indiscriminado de leña y carbón del siglo XIX y principio del siglo $\mathrm{XX}$; para la recuperación de los suelos con malos drenajes y sin regadío, especialmente en las zonas norte del valle de Santiago.

Sin duda el impacto de tales medidas estaba llamado a generar un cambio positivo radical no sólo en el paisaje, sino también en la ecología, economía, y modo de vida de la región urbana. Entre los efectos directos estaría la posibilidad de intensificar el uso de los recursos turísticos y recreacionales de la región, multiplicando los lugares y centros de esparcimiento en valles, lagos, lagunas, alta montaña y otros.

El conjunto de políticas metropolitanas del Plan Intercomunal de Santiago aprobado desde 1960, debía servir de guía a los municipios y servicios estatales sectoriales, los que debían perfeccionarlas, sea a través de los Planes Reguladores Comunales y sus respectivos seccionales, o a través de Planes Seccionales específicos.

Por otra parte, la zonificación industrial en varios sistemas, estaba dirigida a constituir parques industriales exclusivos, debidamente integrados a la ciudad, pero evitando al máximo la contaminación atmosférica, asunto complejo por las características del clima y de la orografía del área, y con incidencia, por cierto, en la percepción del paisaje.

El establecimiento de un anillo suburbano, de enlace entre lo urbano y lo rural, en base de parcelas y equipamientos metropolitanos, debía ser estable, dirigiéndose el crecimiento hacia el interior del área o más allá de su borde, en los diferentes satélites.

En todo ello, la definición de una red básica de transporte y vialidad en sus niveles regionales, intercomunales y comunales de primera magnitud fue relevante a la dotación de conexidad y conectividad en el sistema urbano-regional. 


\section{REVISTA DE URBANISMO}

http://revistaurbanismo.uchile.cl

Planificación urbana-regional y paisaje: impronta de los planes 1960-1994 para Santiago de Chile

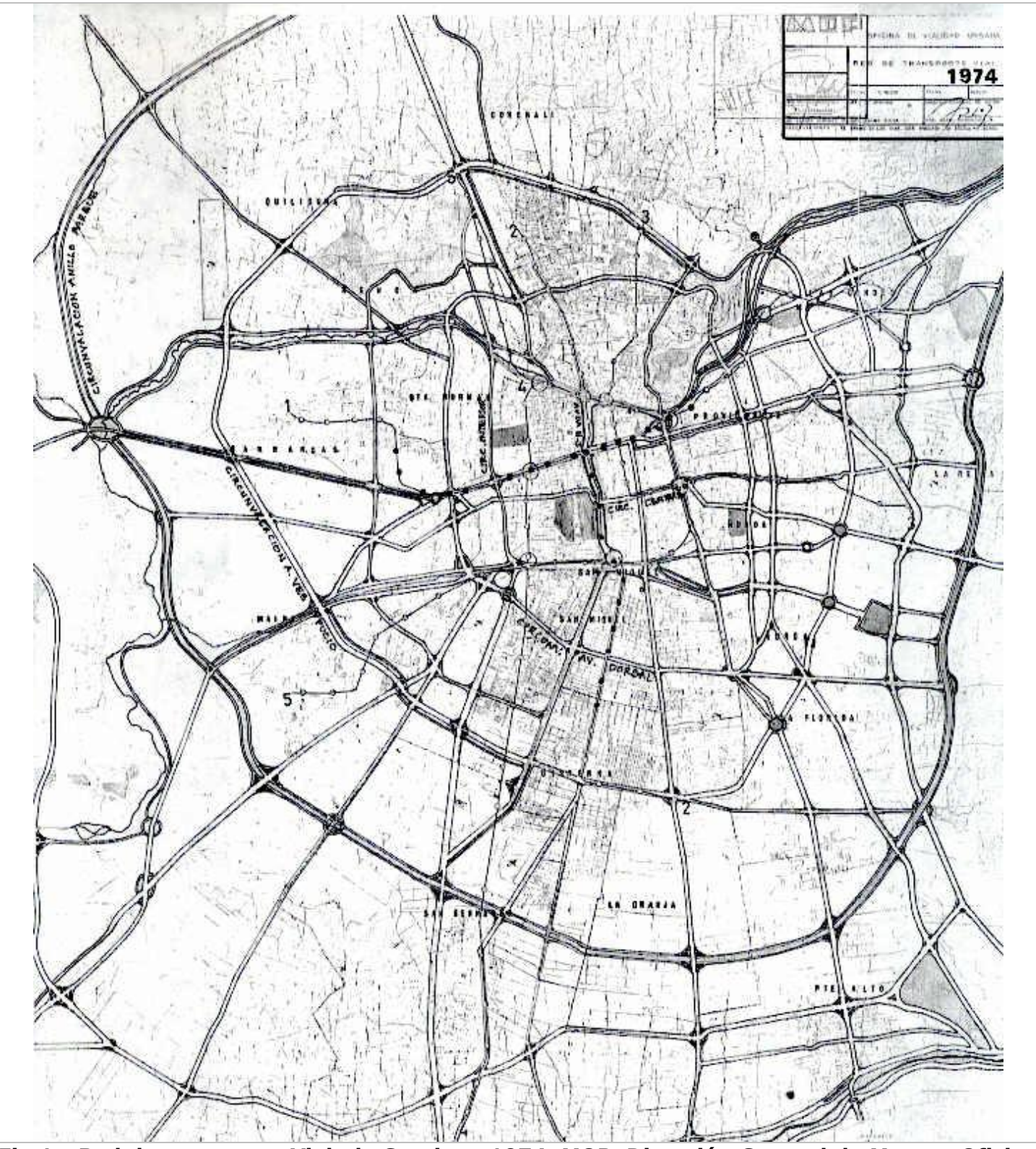

Fig.1.- Red de transporte Vial de Santiago 1974, MOP, Dirección General de Metro - Oficina de Vialidad Urbana (original 1:20.000). Se observa, desde afuera hacia adentro, las circunvalaciones: "Anillo Exterior", "Anillo Parque", "Américo Vespucio", "Dorsal", "Interior", y "Central".

Fte.: Archivo de J. Parrochia B., 2001. 
DIVERSIDAD EN LA VIALIDAD

El sistema vial de 1960 incorporó los siguientes conceptos y reservas:

\section{Carreteras de Acceso al Gran Santiago}

Carretera Panamericana; Ochagavía; Camino a San Antonio (Avda. P. Aguirre Cerda); Camino a Valparaíso, por Lo Prado; Camino Macul - Las Vizcachas.; Avenida Vicuña Mackenna.

Anillos de Circunvalación de las Comunas Periféricas

Anillo exterior

Anillo C. Américo Vespucio

Anillo Dorsal

Sistema de Distribución Intermedio

Anillo Intermedio

Vías Radiales Intercomunales (complementarias del sistema)

Avenidas Parques ${ }^{15}$

Caminos Turísticos ${ }^{16}$

En el estudio Santiago: un plan para una ciudad armoniosa (1985), su autor, el arquitecto Raúl Irarrázabal ${ }^{17}$, anotó el aporte paisajístico de las "nuevas vías de circulación" propuestas en el PRIS de 1960, toda vez que focalizaron elementos relevantes del macro-paisaje:

"Las vías rápidas y las vías parques nuevas abren a los habitantes de Santiago aspectos desconocidos de la geografía natural y humana que no dejarán de asombrarnos. La avenida Kennedy, con su trazado recto enfrenta de manera espectacular el macizo de El Plomo, que domina toda la cuenca de Santiago. La avenida Manquehue con su trazado sinuoso enfoca desde diversos ángulos este cerro de forma escultórica con su cima plana. La rotonda en el cruce de avenida Kennedy y Vitacura es una hermosa plaza vehicular donde convergen varias avenidas, limitada por un conjunto de torres, y con la vecindad del río Mapocho, de los parques El Golf y de Las Américas".

\footnotetext{
${ }^{15}$ Vid. infra pto.1.1.4.

${ }^{16}$ Vid. infra pto.1.1.4.

17 IRARRAZABAL, C., Raúl, Santiago: un plan para una ciudad armoniosa, Ediciones Universidad Católica de Chile, Escuela de Arquitectura, diciembre de 1985, 334 págs., ilustradas.
} 


\section{REVSTA DE

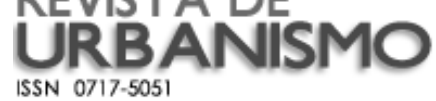

http://revistaurbanismo.uchile.cl

Planificación urbana-regional y paisaje: impronta de los planes 1960-1994 para Santiago de Chile

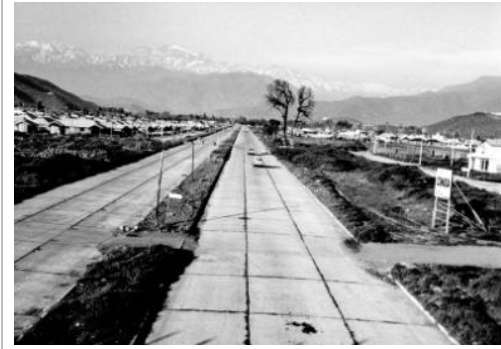

Fig.2.- Avda. Kennedy, vista al oriente. Archivo J.P.B. (

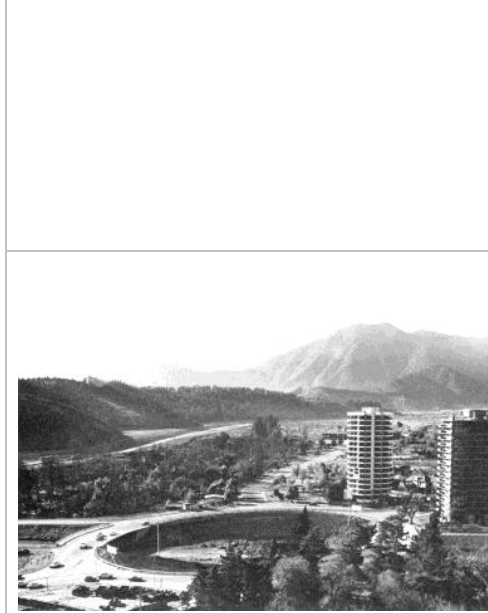

Fig.5.-Rotonda Vitacura, vista al oriente.

F.H. Archivo de J.P.B. (C)

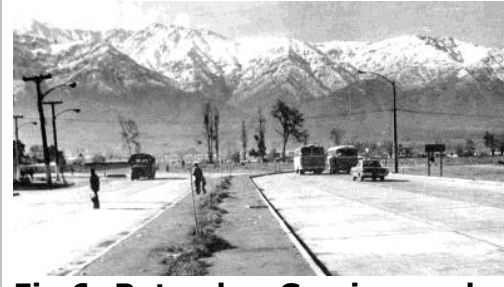

Fig.6.-Rotonda Grecia y la cordillera de Los Andes. F.H. Archivo de J.P.B. (

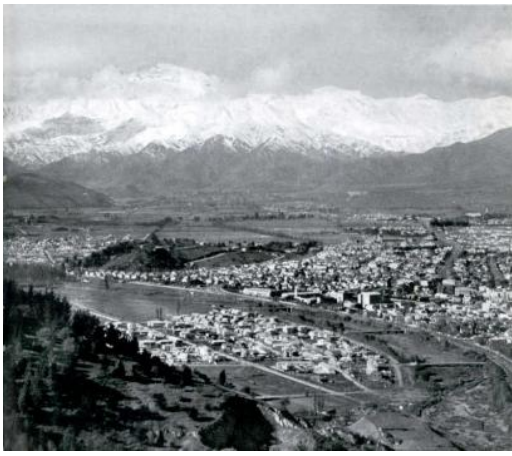

Fig.3.- Vista al oriente, sobre el barrio de Pedro de Valdivia Norte, con el área de futuro desarrollo a partir de la Avda. Kennedy, al fondo, 1958 Gerstmann, op.cit.

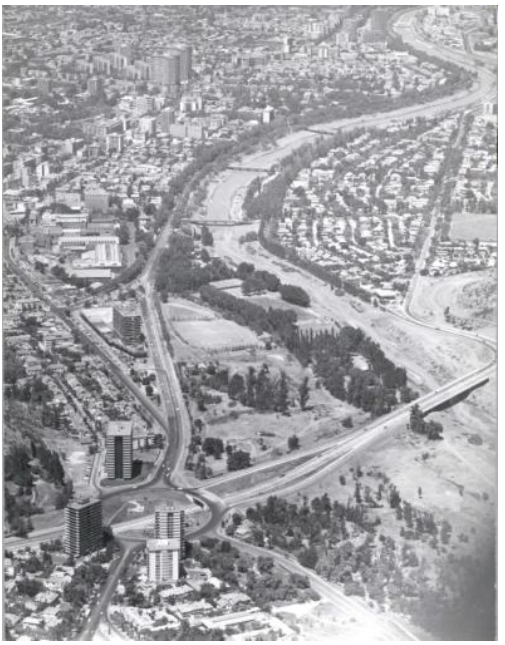

Fig.7.-Rotonda Vitacura - La Portada, vista al poniente, sobre Providencia, río Mapocho y barrio Pedro de Valdivia Norte F.A.O. Archivo de J.P.B @

(c)

Norte,

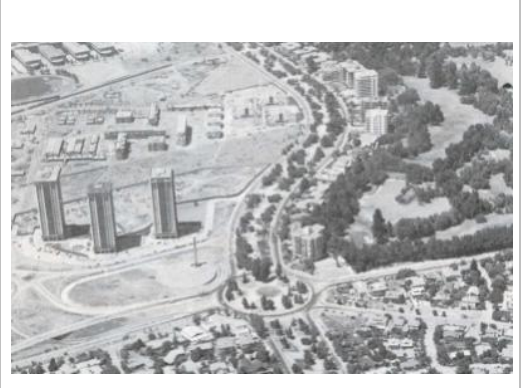

Fig.4.- Trébol Kennedy Circunvalación Américo Vespucio. F.A.O. Archivo J.P.B. (c)

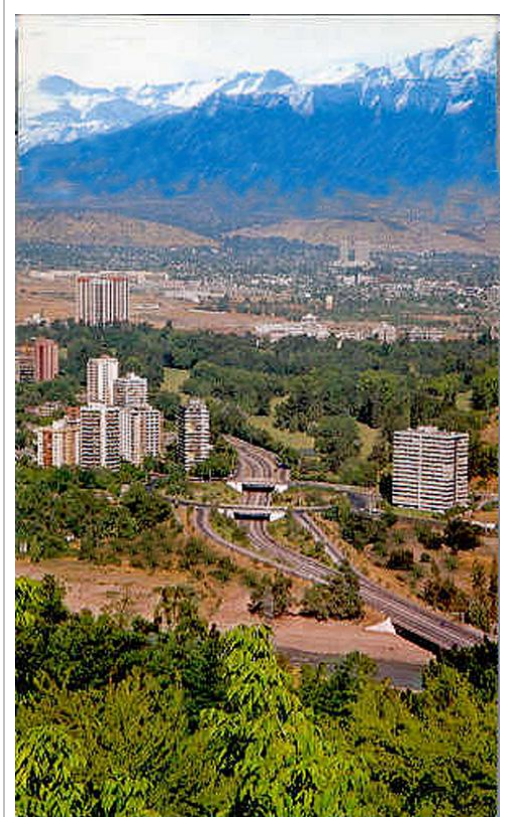

Fig.8.-Complejo Vitacura Kennedy, c 1975. 
Si bien, según Prager $^{18}$, el goce que nos proporciona la naturaleza no es el mismo que aquel que sentimos ante una obra de arte, existe una contemplación de la naturaleza frente a la cual un "individuo educado en el estudio de las obras de arte", buscará formas, líneas y colores armoniosos sacados de las confusas impresiones de la naturaleza. Tales visiones, señala Prager, no son, sin embargo, un goce natural, sino una actividad del espíritu, la que tratándose de tipos creadores se cristalizan en una manifestación de arte. Por otra parte, Prager señalaba:

"Han de crearse recintos para vivir y para trabajar, para la devoción y el recreo. El arte entra a actuar en tales creaciones sólo después de haberse resuelto el problema objetivo conforme a sus exigencias".

Sin duda, en el caso de la planificación de Santiago, los autores intentaron coordinar los insoslayables aspectos incidentes en el funcionamiento de una metrópolis que llegaría a tener 6 millones de habitantes al año 2000, con la posibilidad de capturar presencias de macro paisaje excepcional de la cuenca de Santiago. El potencial a desarrollar en proyectos seccionales funcionales y paisajísticos en lo referido a paisaje intermedio y micro-paisaje en la ciudad, quedaba abierto, dando lugar a la participación de numerosos otros autores. Es el caso del paisajista alemán antes citado, Oscar Prager, quien aportó el diseño de los espacios verdes en el Seccional Avenida Parque Isabel Riquelme, proyecto vial en los planes de $1960^{19}$.

\subsection{Sobre integración del medio natural y el medio artificial}

En primer lugar, y en grandes líneas, los planes reguladores regionales y microregionales de Santiago realizados en 1958 - 1960, para servir de base al Plan Regulador Intercomunal de Santiago, tuvieron los siguientes objetivos que dan cuenta de una voluntad de coordinación mayor entre naturaleza y proyectos ${ }^{20}$ :

Se trataba de administrar el crecimiento de las metrópolis incluidas dentro de la IV Región (de la época), de tal forma que, sin impedir su expansión natural originada en sus recursos y sus relaciones geopolíticas internas y externas, se lograra un conjunto de asentamientos urbanos a escala del hombre, en contacto permanente con la naturaleza, protegiendo los ecosistemas de la región y desarrollándolos armónicamente.

Respetando la calidad de los suelos, se sacó el mejor partido de la hidrografía y de la orografía, proponiendo reforestar todo el territorio entre la cota 700 y 1.000 de altura, evitando la pérdida de suelos agrícolas productivos, orientando las nuevas áreas urbanizadas en suelos de menor calidad. Pero, sobre todo, manteniendo formas urbanas incorporadas a la naturaleza en el diseño de los centros poblados, evitando la

\footnotetext{
18 PRAGER, op.cit.

${ }^{19}$ Lamentablemente, luego de haber realizado este trabajo le sorprendió la muerte.

20 PARROCHIA B., J. (autor y co-autor de contenidos), PAVEZ R., M. I. (compiladora), 1994, op.cit.

Revista de Urbanismo $\mathrm{N}^{\circ} 6$ - Julio de 2002
} 
Planificación urbana-regional y paisaje: impronta de los planes 1960-1994 para Santiago de Chile

ciudad redioconcéntrica de crecimiento repetitivo, monótono y alejado de su cuadro natural.

Es por ello que el núcleo principal de la ciudad de Santiago se bosquejó sobre un esquema de estrella de siete puntas, permitiendo que "cuñas verdes" de la naturaleza penetraran hasta su centro por accidentes geográficos, como son el Manquehue, el Bosque de Santiago, y el cerro San Cristóbal; el cerro Renca y el cerro Colorado; el río Mapocho y el zanjón de la Aguada, tanto al occidente como al oriente; o por accidentes artificiales, en base de equipamiento metropolitano, como fueron el fundo La Laguna y el gran Centro de Abastecimiento Agrícola Occidental, el Aeropuerto Los Cerrillos, La Castrina de la Universidad de Chile, etc.

Los cuatro centros metropolitanos de la Región se extendían en forma longitudinal a lo largo del Océano Pacífico, LLolleo - San Antonio - Cartagena; Valparaíso - Viña, o a lo largo de los ríos del valle del Aconcagua y del Cachapoal, manteniendo en todo el espacio de la Región, una constelación de centros de diferentes tamaños de acuerdo a su especialidad, ya sea industrial, agrícola-industrial, agrícola, residencial o recreacional.

En el caso de la Micro-Región de Santiago IV-B (de la época), un gran anfiteatro, producido por el inicio norte del valle central de Chile, en la cuenca media del río Maipo y conformado fundamentalmente de norte a sur, por los ríos Puangue, Lampa y Colina, en sentido norte - sur; el Huechuraba, el Mapocho y La Aguada, el propio río Maipo en sentido oriente - poniente, y el Clarillo, el Paine y el Angostura, en sentido sur a norte, fue el espacio base del planeamiento.

Se conformó así, lo que el urbanista del plan, arquitecto Juan Parrochia, denomina una "pauta de desarrollo Micro-Regional"21, sobre un esquema de cuatro ejes hidrográficos centrales, proyectados hacia el norte y el sur, por tres ejes verticales principales y tres ejes secundarios en cada una de esas direcciones.

De esta forma, el núcleo central de la Metrópoli de Santiago y sus satélites residenciales inmediatos, quedaban apoyados sobre cuatro cerros - islas: Renca, San Cristóbal, Chena y VizcacHás., entre la Cordillera de los Andes y la Cordillera de la Costa.

"En esta interesante estructura geográfica, uno de los más hermosos marcos urbanos entre las grandes ciudades del mundo, se conforma la Metrópoli de Santiago, irradiándose hacia la región y hacia el país, a través de Corredores de Transporte conformados por caminos, carreteras, vías férreas, oleoductos y gaseoductos, redes eléctricas de alta tensión, redes telefónicas, rutas aéreas y marítimas, directas o indirectas, redes de agua potable, redes de aguas servidas, etc., produciéndose a través de la historia, sucesivos umbrales tanto naturales como producidos por el hombre (conventos, "chácaras" de producción hortícola,

\footnotetext{
${ }^{21}$ Idem. 


\section{REVSTA DE UMRB BANBSA}

$\mathrm{http}: / /$ revistaurbanismo.uchile.cl

Planificación urbana-regional y paisaje: impronta de los planes 1960-1994 para Santiago de Chile

cementerios, hospitales, industrias, canales, talleres ferroviarios y tranviarios, instalaciones militares, terminales aéreos, rodoviarios y ferroviarios, parques suburbanos, etc.). ${ }^{22}$

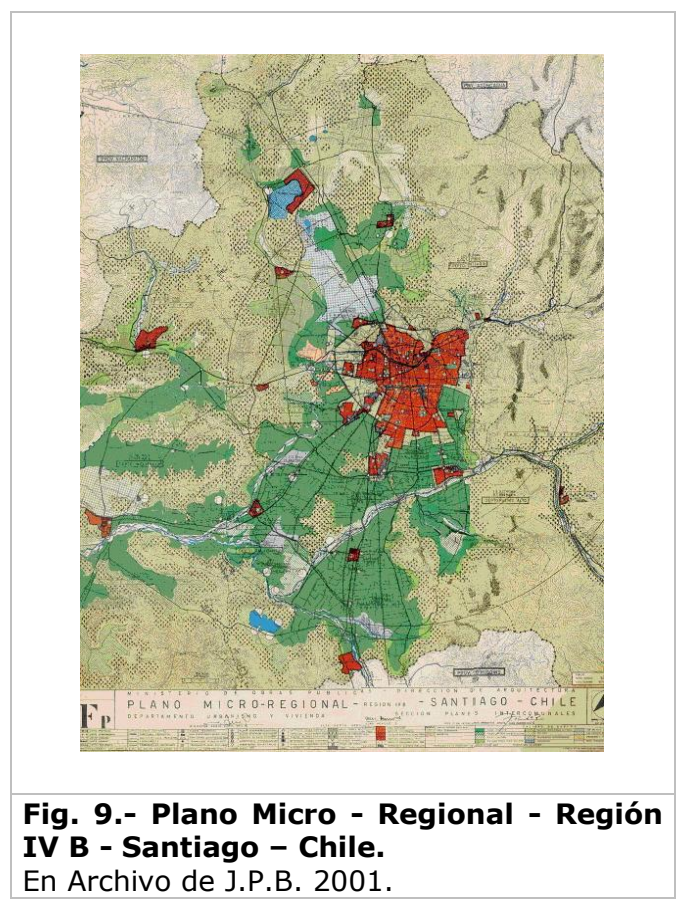

En el Plan Regulador Intercomunal de Santiago y en la Micro- Región IV-B, el núcleo central de Santiago se irradia hacia el territorio regional y nacional por nuevos corredores ubicados en las "cuñas verdes", para lograr una comunicación y un transporte más rápido, eficiente y paisajísticamente más logrado, al integrarse rápidamente al área agrícola y rural del entorno.

Como proposición específica puede mencionarse, a modo de ejemplo, que "Plan Microregional - Región IVB - Santiago de Chile" 1960, MOP, propuesto conjunta y coordinadamente con el PRIS 60-94 MOP, desde 1960 -y lamentablemente, desatendido desde mediados de los años 1960s-, contempló un Sistema de Costaneras del río Mapocho, corredor metropolitano fundamental Oriente - Poniente desplegado entre la Cordillera de Los Andes y la Cordillera de la Costa, con aproximadamente 350 metros de ancho, comprendidas las áreas verdes que contempló, integrando proyectos de parques laterales existentes desde principios de siglo (Parque Forestal, Parque Centenario -hoy Parque de los Reyes-, Parque Providencia).

22 Idem.

Revista de Urbanismo Nº6 - Julio de 2002 
Como consecuencia, el sistema costaneras del corredor metropolitano fundamental Oriente - Poniente, aparece simultáneamente en el PRIS 1960-94 MOP, desplegado a todo lo largo de río Mapocho entre los límites del área definida como intercomunal (Parque intercomunal Cuenca del Mapocho, con 690 Hás.)

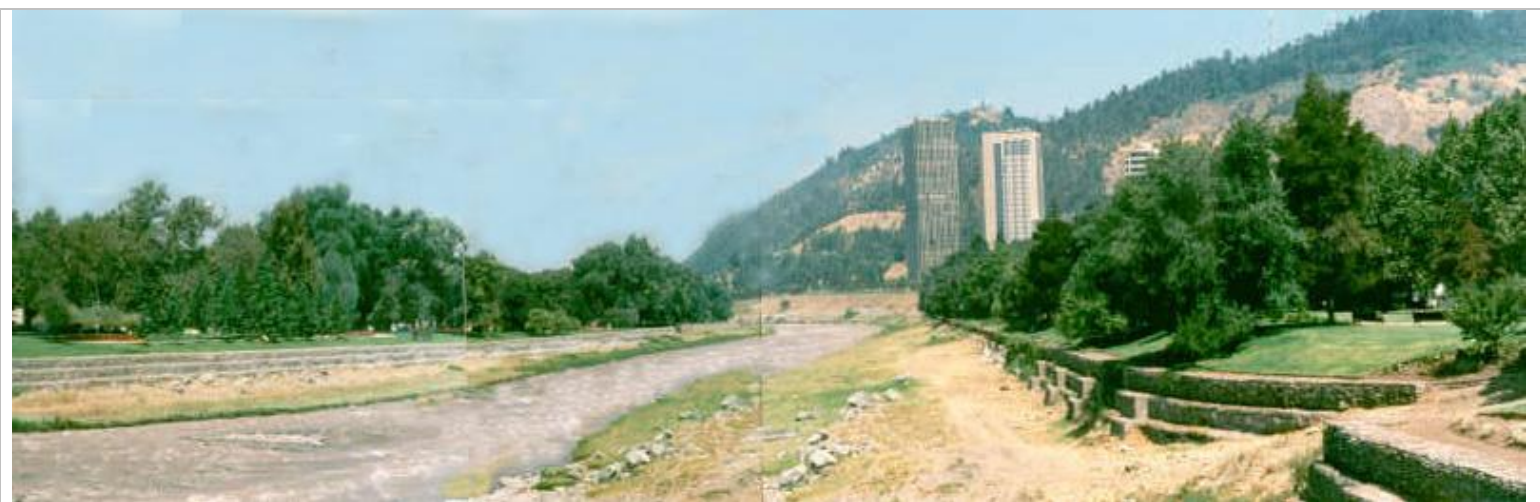

Fig.10.- Vista del sistema parque del río Mapocho, desde el puente Pedro de Valdivia hacia el poniente, al fondo antiguas canteras ya plantadas, 1996, M.I.P.ㅇ

El proyecto seccional "Sistema Costaneras del Corredor Metropolitano Fundamental Oriente - Poniente, Tramo Bulnes - Complejo Vial Avda. Norte - Sur, 1969-1975MOPT"23, dispuso adicionalmente, grandes terraplenes en el borde sur del río Mapocho realizado con material de las excavaciones del Metro, para efectos de trasladar la línea férrea ubicada junto al límite sur del Parque Centenario, y acoger la futura Línea 5 del Metro (proyecto original).

De igual forma se estableció una superficie para la Cuenca del Río Maipo, frente a Puente Alto, aproximada de 30 Hás.

$\mathrm{Si}$, por otra parte se observa el listado de parques del plan, todos los cerros que rodean Santiago quedan bajo el estatus de parque, constituyendo un cordón verde mayor para la recreación tanto de la población prevista en la micro-región como en la metrópolis:

Parque Cerro Alvarado (Las Condes); Parque Cerro El Observatorio (Las Condes); Parque Cerro Manquehue (Las Condes); Parque Cerro Colorado Quilicura); Parque Cerro Renca (Quilicura); Parque Cerro Vizcacha (Puente Alto); Parque Cerro Negro (San Bernardo); Parque Cerro Chena (San Bernardo); Parque del Cerro Blanco (Santiago).

\footnotetext{
${ }^{23}$ PAVEZ R., M. Isabel, I. Responsable; Co-I.: Arqtos. Antonio SAHADY V. y Martín DURÁN A.; Colaborador: Arqto. Patricio DUARTE G., El Potencial de Espacios Públicos y Semipúblicos del Pericentro Histórico de Santiago: Recomendaciones integrales al trazado urbano y arquitectura patrimoniales en la Comuna de Independencia, (Financiado por Concurso F.A.U. Proyectos de Investigación Arquitectura y Urbanismo Geografía y Diseño 1999 (duración 1 año.). Informe final en III Tomos inéditos (marzo 2001). 
Por último, podemos destacar, entre otros, la disposición de reservas forestales y agrícolas al oriente de la ciudad, en el piedmont andino, entre el límite urbano intercomunal y el límite suburbano, para efectos de mantener áreas de absorción de flujos de agua y con ello contribuir a evitar las inundaciones de la ciudad, entre otros beneficios ${ }^{24}$.

\subsection{Sobre instauración de circuitos y espacio público}

Los planes de 1960 propusieron circuitos integradores del espacio intersticial público tanto al interior del medio urbano, como entre medios urbano y rural, mediante las llamadas Avenidas Parques y los Caminos Turísticos, los que fueron definidos de la siguiente manera:

Avenidas Parques: con una o dos calzadas para tránsito lento contiguas a una franja de área verde, continua o discontinua, con arboledas, jardines y juegos para niños. Estas avenidas relacionan generalmente dos o más Parques Comunales con las áreas especiales. Se incluyeron las siguientes Avenidas:

\footnotetext{
- Terrenos destinados anteriormente a la Carretera Panamericana en las C. de La Cisterna y San Miguel, y su prolongación en la C. de Santiago, en el tramo: Parque Cousiño por el N., hasta la prolongación hacia el O. de la Avda. I. La Católica en la C. La Cisterna. Ancho $100 \mathrm{~m}$.

- Gran Avenida. Desde Ferrocarril de Circunvalación por el N., hasta la calle Salesianos por el S. Ancho $60 \mathrm{~m}$.

- Parque I. Riquelme. Desde V. Mackenna por el E., hasta P. Aguirre Cerda, por el O.

- Avda. que unirá el Estadio Nacional, Estadio Colo-Colo y el Parque Intercomunal N6 (La Castrina). Ancho $60 \mathrm{~m}$.

- Avda. que une el extremo oriente del Parque I. Riquelme, desde V. Mackenna hasta el Parque de la Viña Macul por el E. Ancho $60 \mathrm{~m}$.

- Avda. que une el extremo poniente del Parque I. Riquelme desde P. Aguirre Cerda hasta el camino Los Pajaritos. Ancho $60 \mathrm{~m}$., de acuerdo al anteproyecto del Plan Regulador de la C. de Maipú.

- Avda. Dorsal. Desde la C. de Conchalí y su prolongación hacia el O. a través de la C. de Renca hasta la ribera N. del Río Mapocho. Ancho $60 \mathrm{~m}$.

- Avda. Tobalaba. Desde el Río Mapocho por el N., hasta el Camino Departamental por el S.

- Avda. Manquehue. En C. de Las Condes, desde el río Mapocho por el N., hasta Parque Interc. $N^{\circ 7}$ por el S.

- Avda. Francisco Bilbao. Desde Avda. Manquehue, por el O., hasta el área futuro cementerio en C. de Las Condes, por el E.

- Diagonal proyectada en Plano Regulador de Ñuñoa, desde el Parque de la Viña Macul, por el E., su prolongación hacia el O. a través de la Avda. Sur y la bifurcación de estas, a través de la Avda. Matta y el Parque Bustamante.
}

\footnotetext{
${ }^{24}$ Dado que, cuarenta años después, luego de cada inundación y por diversos medios algunos denuncian que las ciudades chilenas están mal planificadas y mal diseñadas, cabe recordar que quienes desataron la desplanificación y desregulación urbana en Chile, derogaron en 1979 medidas básicas que se iban multiplicando en beneficio del buen funcionamiento de la ciudad desde la aprobación del Plan Regulador Intercomunal de Santiago 1960-1994. Ello modificó profundamente -entre otros efectos negativos- el fenómeno de escurrimiento de las aguas en la ciudad, sin haberse tomado otras medidas para enfrentar las consecuencias. En tanto, se proclamó desde sus cargos y poder políticos que todo estaba "bajo absoluto control", sin consideración a las advertencias de los planificadores urbanos que indicaban que la pavimentación y cobertura de miles de hectáreas, hasta entonces expresamente excluidas del uso urbano se traduciría, en cualquier momento del futuro -hoy-, en volúmenes de agua inmanejables en loca carrera por las superficies impermeabilizadas.
}

Revista de Urbanismo $\mathrm{N}^{\circ} 6$ - Julio de 2002 
- Nuevo camino a Valparaíso por Lo Prado, tramo entre la Avda. Ecuador, por el E., y el cruce del río Mapocho, por el O. (paralela al futuro camino Lo Prado por el lado N.). Se consultó faja destinada a área verde y calle de tránsito local de $70 \mathrm{~m}$. de ancho, al $\mathrm{N}$. de la faja destinada a dicha carretera.

\section{Caminos Turísticos:}

En el sector oriente del Gran Santiago se estableció un camino cuyo trazado se indicó en el Plano de Zonificación atravesando las comunas de Puente Alto, La Florida, Ñuñoa, Las Condes, que se extiende desde Las VizcacHás., por el sur, hasta el Cerro Alvarado, por el norte.

\subsection{Sobre el incremento de bienes de uso público}

Por último, los planes establecieron legalmente la patrimonialidad pública de manera expresa para las áreas proyectadas o confirmadas, manifestando con ello la voluntad de resguardo a través del tiempo de estos bienes públicos y sus valores múltiples, incluido el valor paisajístico.

En el Plan Intercomunal de Santiago se preservó legalmente el cerro San Cristóbal, el cerro Santa Lucía, el Parque Cousiño, la Quinta Normal y muchos otros, declarándolos con la calidad jurídica de Areas Verdes y Bien Nacional de Uso Público a partir de 1960.

Debe mencionarse finalmente, que los realizadores del Plan, plantaron por diez años una media entre 10.000 y 20.000 árboles en el área de Santiago y, posteriormente, a través de las obras del Metro de Santiago, se repuso como espacio verde el espacio Ilamado tradicionalmente "Alameda de las Delicias", el cual en 1969 presentaba un aspecto de gran deterioro, conteniendo áreas de estacionamiento de autos, depósitos de camiones, e incluso un taller de reparación de buses, según se constató en un recorrido por la ciudad en septiembre de ese $a n ̃ o^{25}$.

De igual forma, en otra acción de doble efecto, se trasladó material desde las excavaciones del Metro hasta las canteras del cerro San Cristóbal para generar las actuales terrazas que hoy podemos ver plantadas.

El trazado de la Línea $\mathrm{N}^{\circ} 2$ del Metro, se fijó en 1970 fuera del Parque Subercaseaux, sin embargo, posteriormente fue desplazado hacia el Parque. ${ }^{26}$.

\footnotetext{
25 "Reportaje a Santiago", en CA N6, octubre - noviembre de 1969, pp.21-22.

${ }^{26}$ PARROCHIA BEGUIN, Juan 1979, op.cit.
} 


\section{REVGTA DE \\ USR B B A}

http://revistaurbanismo.uchile.cl

Planificación urbana-regional y paisaje: impronta de los planes 1960-1994 para Santiago de Chile

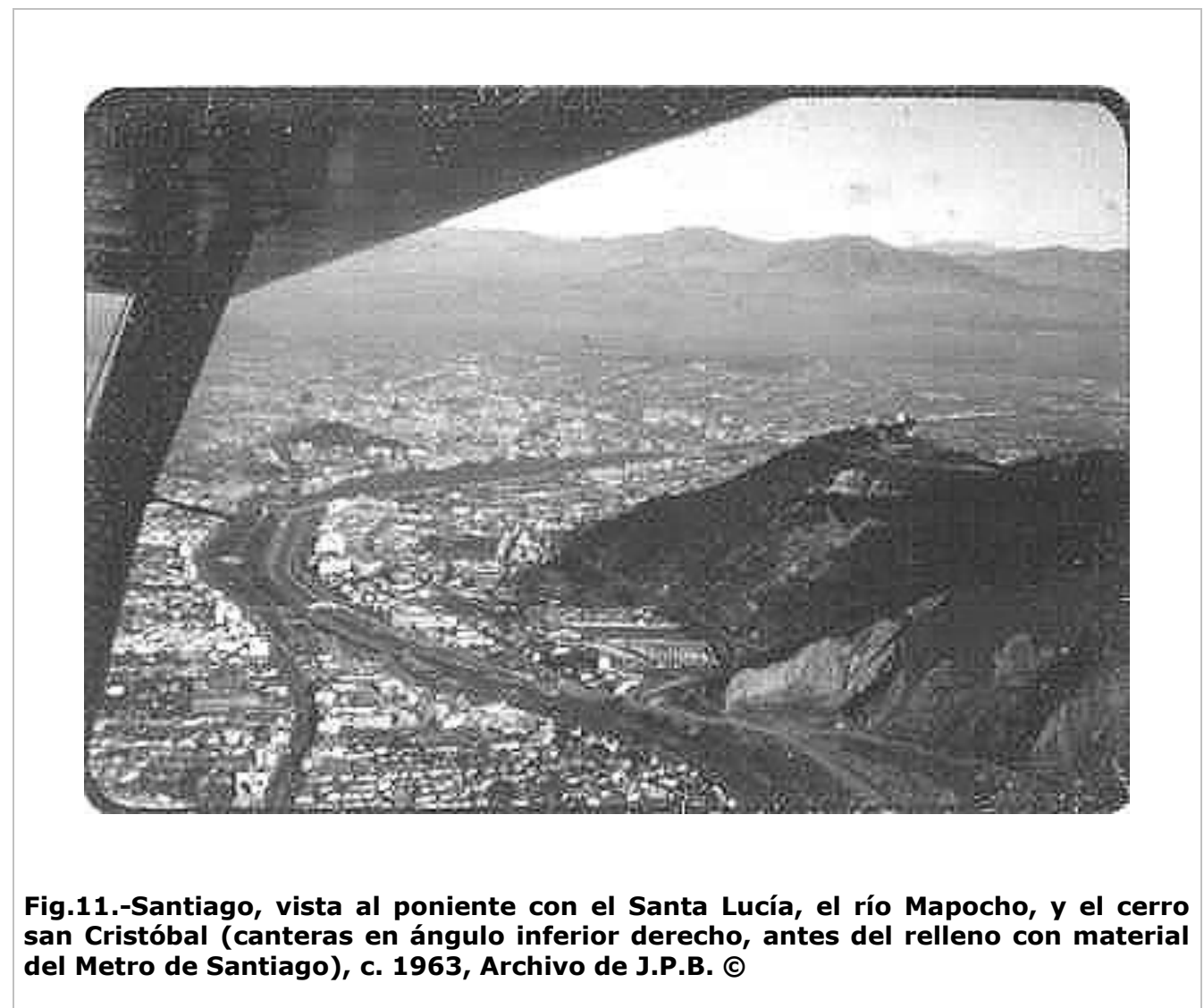




\section{REVISTA DE \\ URR}

http://revistaurbanismo.uchile.cl

Planificación urbana-regional y paisaje: impronta de los planes 1960-1994 para Santiago de Chile
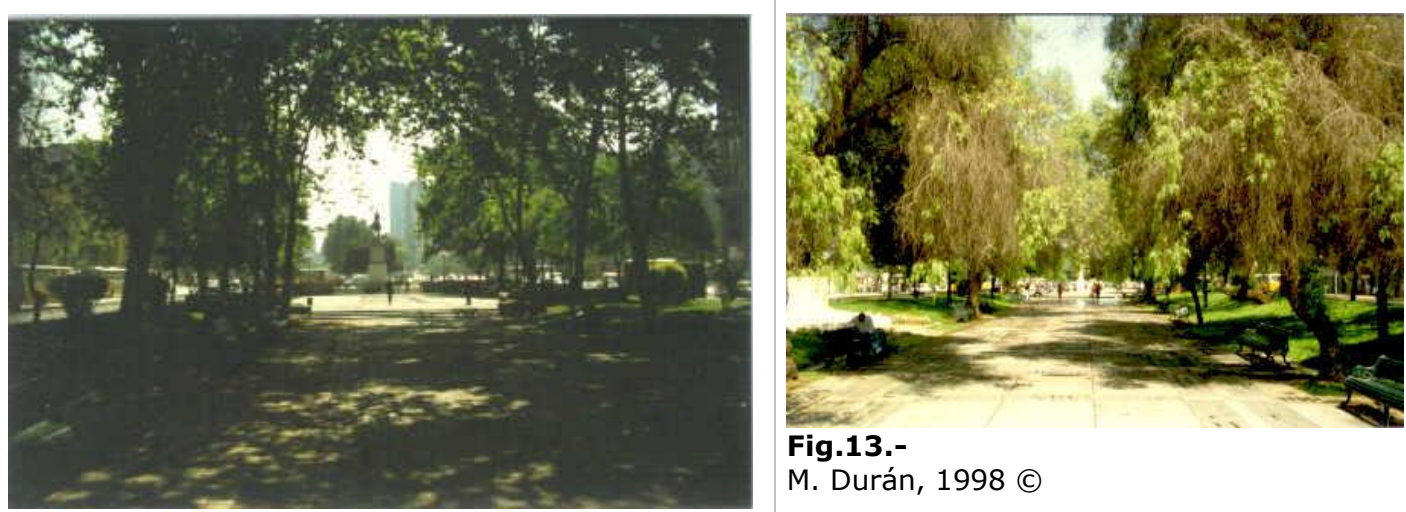

Fig.13.-

M. Durán, 1998 @

Fig.12.-

Paseo central en Avda. del Libertador B. O'Higgins, proyecto de Claudio Barros y Hernán Pino, Dirección General de Metro - MOP, 1974 (esta foto y las cuatro siguientes). Fotos M. Durán, 1998 (c)

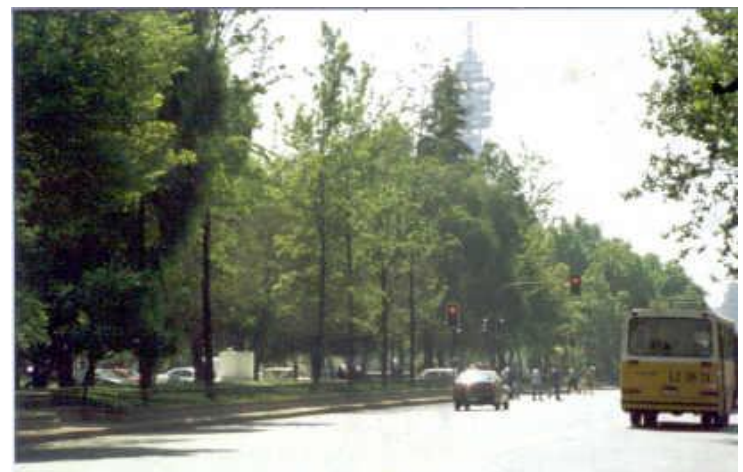

Fig.14.-

M. Durán, 1998 C

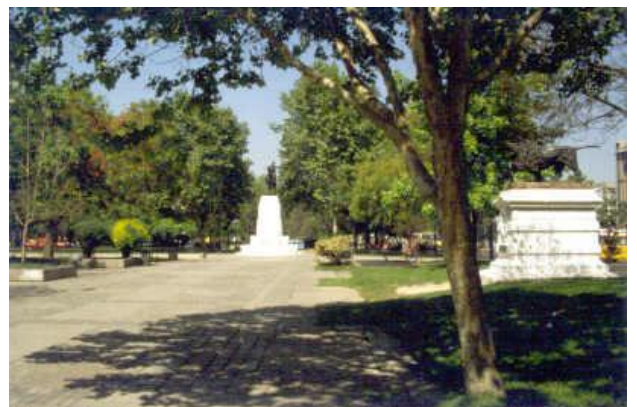

Fig.15.-

M. Durán, 1998 @ 


\section{Influencia de los altos inspiradores ${ }^{27}$}

Al comienzo de este escrito afirmamos también que la formación de los autores de estos planes en la entonces "Facultad de Arquitectura" de la Universidad de Chile, entre 1947 y 1952 y, posteriormente, en otras instituciones en el extranjero, estaría sugiriendo, una fuerte influencia en sus proyectos de las escuelas de Sir Patrick Geddes (1854-1932), Lewis Munford (1895-1990), y los arquitectos Robert Auzelle (1913-1983), Gaston Bardet (1907-1989), todos autores cuyas obras constituyeron lectura obligatoria por varias décadas en dicha escuela ${ }^{28}$, y del precursor chileno Luis Muñoz Maluschka (1896-1974) en las materias de interés ${ }^{29}$.

En relación con esta hipótesis destacamos algunos de los conceptos más relevantes:

a) consideración del espacio habitable como una totalidad sistémica, integrada, que comprende tanto los espacios urbanos como los rurales en interacción;

b) necesidad de realizar estudios multidisciplinarios previos del área territorial a ordenar;

27 Se consultó las siguientes fuentes:

CHOAY, Françoise, L'urbanisme, utopies et réalités, une anthologie, Editions du Seuil, 1965.

BARDET, Gaston, L'urbanisme, (1945), Ed. Que Sais-Je?, $10^{\circ}$ ed. actualizada por su autor en 1983.

GEDDES, Patrick, "La Sección del Valle", en LEWIS, D., La ciudad: problemas de diseño y estructura, Ed. G.G., S.A., Barcelona, 1970.

INSOLERA, Italo, "Lewis Munford 1895-1990. Uno "scrittore" tra cultura e storia della città", en: Urbanistica, N097, dic. 1989, pp.101-102.

-Dictionnaire de I'Architecture du XX siècle, Ed. HAZAN-IFA, 1996, y CUILLIER, F. (B. Écrement y M.Paquet, colab.), Interview "Gaston Bardet", en Revista Metrópolis, IIIe année, Nos 28-29-30, 1977, ambos por gentileza de Bernard ÉCREMENT, Director de la Revista Urbanisme, julio de 1998.

-BAUDOUI, R., Planification territoriale et reconstruction 1940-1946, U. Paris XII, I.U.P., T. Doctoral, Prof. B.Vayssière, 1984. (Auzelle).

-Revista L'Architecture d'aujord'hui, "20 ans d'Urbanisme appliqué. France, Afrique du Nord", No3, marzo de 1939. (Bardet).

-Revista Arquitectura y Construcción, N014, Santiago de Chile, 1948. (Bardet).

-BARDET, Gaston, L'Urbanisme, Que Sais-Je?, 1983, 10a ed. de obra de 1945, actualizada por Gaston Bardet en 1983.

-Diario El Mercurio de Santiago, días 26 y 27 de Sept. 1948; noticias reiteradas en la sección "Hace 50 años", del mismo diario, los días 26 y 27 de Sept. 1998. (Bardet).

-DELFANTE, Charles, "Robert Auzelle", en Revista Urbanisme,Voirie/ Techniques/ Paysages, N0200, p. 31

-RANDET, Pierre et als., "Hommage a Robert Auzelle", en Revista Urbanisme, Images, Langages, Espaces de communication, N0203, Sept. 1984, pp. 42-50.

28 Hás.ta los años 1970s. Auzelle y Bardet, fueron además, Jefe (Ministerio de la Reconstrucción, en Francia), y Profesor (Instituto Superior de Urbanismo Aplicado - Escuela de Arquitectura Saint-Luc, en Bélgica) del Arqto. Juan Parrochia Beguin, co-autor de los planes, Orden de Mayo al Mérito, Argentina, 1970, Premio Nacional de Urbanismo, Chile, 1996.

${ }^{29}$ Entre otros. (Luis Muñoz fue Profesor de la Universidad de Chile, entre 1947 y 1952, coincidiendo con el período de formación de sus alumnos más distinguidos). Adicionalmente, puede mencionarse como uno de los proyectos de referencia - relevante en la época en que los Arquitectos Juan Honold D. y Juan Parrochia B. estudiaron la carrera de Arquitectura-, el Plan Regional y del Condado de Londres, de Abercrombie y Forshaw, en 1944, en el cual se distinguió: una zona interior (condado y barrios periféricos), la zona suburbana, y la zona exterior, comprendiendo esta última el llamado cinturón verde y el territorio circundante Hás.ta 60-80 Km. desde el centro de Londres; aquí debería producirse todo el aumento futuro, fuera por expansión de las ciudades menores ya existentes, o por creación de nuevas ciudades satélites.

Revista de Urbanismo Nº - Julio de 2002 
Planificación urbana-regional y paisaje: impronta de los planes 1960-1994 para Santiago de Chile

- c) generación de directrices de planeamiento que se irán implementando día a día, mediante estudios y proyectos seccionales en los cuales participarán numerosos autores;

- d) diversificación de las respuestas;

- e) elevación de la densidad de población en medio urbano;

- f) el espacio regional como un espacio de interés también paisajístico y disfrute colectivo.

\subsection{Sobre espacio habitable como una totalidad sistémica}

La aplicación del método del "Regional Survey", propuesto por Geddes a partir del cual no era suficiente limitarse al análisis de la ciudad, sino que era necesario analizar toda la región en la cual estaba la entidad urbana, a la vez que considerar todos los puntos de vista posible, tanto el sociológico, como el geográfico, el histórico y el económico (1907), es sin duda una realidad en el caso de los autores de la planificación de 1960, toda vez que abordan un plan tridimensional abarcando aspectos regionales, microregionales e intercomunales en forma coordinada.

Bardet por su parte, llegó a indicar la obsolescencia del término tradicional de Urbanismo, toda vez que los problemas del asentamiento humano están en todo el territorio habitable: complejo aglomeración-región. De la región provienen los materiales utilizados en su estructura física, de ella provienen los abastecimientos para la vida de sus habitantes y ella le proporciona el marco de su paisaje caracterizador.

Auzelle también destaca la imperiosa necesidad de abandonar las improvisaciones en materia de ordenamiento territorial y de coordinar las diversas formas de ocupación en todo el territorio habitable.

En el concepto de Muñoz Maluschka, el alcance que tiene el concepto de "plan territorial" requiere, ante todo, la comprensión de lo que constituye el "plan regional" en el urbanismo. Iniciado como una actividad esencialmente artística, evolucionó conjuntamente con la arquitectura de la época, hasta abarcar los problemas de las funciones económicas y sociales de los núcleos poblados ${ }^{30}$ :

"El urbanismo contemporáneo actúa basado en un plan regional, cuya finalidad es la disposición armónica de los distintos centros de trabajo en relación con sus centros de residencia correspondiente. El plan regional, sin embargo, por ser restringido, no ha podido abarcar el problema más amplio del urbanismo, es decir, el estudio del funcionalismo económico y social de las diferentes categorías de núcleos poblados, aldeas, pueblos, ciudades y metrópolis, estudio que el urbanista rumano Sfintesku lo denominó "Super-Urbanismo". Esta denominación no ha sido muy feliz, porque en este caso se analizan los núcleos poblados no como una causa, sino como simple efecto o consecuencia de las actividades económico-sociales del territorio, en una

30 PAVEZ R., M. Isabel (compiladora), Luis Muñoz Maluschka. Escritos, Edición del Departamento de Urbanismo de la F.A.U. de la Universidad de Chile, nov. De 1993, 86 págs 
Planificación urbana-regional y paisaje: impronta de los planes 1960-1994 para Santiago de Chile

forma casi análoga como la geografía humana analiza este problema, pero con un objetivo muy diferente. El término de "Planificación Territorial" envuelve, en primer plano, la idea de plan o programa de acción, plan que en el urbanismo abarca únicamente una región. El plan regional debe ser consecuencia de un plan territorial que establece la relación que existe entre los diversos núcleos poblados y la economía del territorio".

Para Muñoz Maluschka, la Región es fundamental para el desarrollo de los centros urbanos, y por ello él promovió y logró en Chile, en el año 1953, el establecimiento de la Planificación Regional como estructuradora básica de todo proceso de Planificación Territorial en el país. Por otra parte, entre el año 1953 y 1958, se determinaron las Regiones de Chile y se estableció la existencia de una sola Región Central, que abarcó Valparaíso, San Antonio y Santiago, con los valles de los ríos Maipo y Aconcagua.

Esta Región, a la que se le asignó en número IV, se dividió en las Sub-Regiones: IV-A: Valparaíso y el Río Aconcagua (Cuenca del Aconcagua); y IV-B : San Antonio, Melipilla y Santiago (Cuenca del Maipo), incluyendo las Micro-Regiones de Santiago y San Antonio.

Cada Micro-Región tuvo Sectores Micro-Regionales, en Santiago, se detectaron por lo menos seis: Lampa-Colina-Til-Til; Pirque-Cajón del Maipo; Buin-Linderos-Hospital; Padre Hurtado-Peñaflor-Talagante; Melipilla-Puangue-San Pedro; Curacaví-Lo Aguirre.

En esta misma forma se estudiaron todas las Micro-Regiones del territorio nacional, con criterios uniformes, configurándose en forma equivalente -sobre una base económica, técnica y social- las regiones del país. Esta modalidad determinó regiones muy diferentes a las actuales, que son más bien administrativas y no basadas sobre iguales criterios $^{31}$.

Los Planes Micro-Regionales surgieron así como subsistemas de los Estudios Regionales. En esa misma época surgieron, a su vez, los Planes Seccionales como subsistemas de los Planes Intercomunales y Comunales. El propio Plan Intercomunal de Santiago incorporó en su aprobación el Plan Seccional Intercomunal de la Avenida-Parque Isabel Riquelme, y su ordenanza exigió la confección de Planes Seccionales Comunales de las micro-zonas industriales, de los centros cívicos comerciales, y otros que fueran necesarios, para fijar mejor las condiciones y requerimientos de la ciudad.

Dentro de la Micro-Región de Santiago se estudió y proyectó el futuro desarrollo de la Metrópoli de Santiago, lo que se denominó Plan Intercomunal de Santiago, cuyo objetivo fue iniciar las bases de un Gobierno Metropolitano. Para estos efectos, se contaría con un Alcalde Mayor designado por los Alcaldes de las Comunas que integraban Santiago, y con el sólo objetivo de presidir la Asamblea de Alcaldes, elegidos por votación popular de Gobierno Local.

\footnotetext{
${ }^{31}$ PARROCHIA B., J. (autor y co-autor de contenidos), PAVEZ R., M. I. (compiladora), 1994, op.cit. 
Lamentablemente esta concepción de los Planes Regionales, Microregionales, e Intercomunales coordinados, fue modificada por el D.S. No 880 M.O.P., de 16 de mayo de 1963. A partir de esta modificación, ya no se exigieron ni los Planes Regionales ni los Planes Microregionales para aprobar un Plan Intercomunal.

\title{
2.2.Sobre estudios multidisciplinarios previos
}

La perspectiva de futuro a partir del estudio y comprensión de los múltiples aspectos que comprendía el área de estudio se encuentra en la planificación de los años 58/60 en Chile. Así queda demostrado desde los análisis presentados en el "Seminario del Gran Santiago" realizado a fines de la década de los años 1950, y por la evidencia del expediente mismo que acompañó la aprobación técnica del plan en 1958, a saber ${ }^{32}$ :

\begin{abstract}
LISTADO DE PLANOS DE ANALISIS EJECUTADOS PARA LA CONFECCION DEL PLAN INTERCOMUNAL DE SANTIAGO

010-01 B - 1952 Planos de Antecedentes Recopilados; 02 A - Abr.1954 Vialidad Existente; 04 A Jul.1954 Aumento de Población 40-52; 05 A - Ago.1954 División Predial Rural; 07 B -Oct.1954 Servicios urbanos-gas, Revisado Jul.1958; 08 B - Nov.1954 Servicios Urbanos - Alcantarillado; 09 A Ene.1955 Tránsito de Automóviles de 8 a 20; 10 A - Mar.1955 Conjunto de Planos Reguladores Comunales; 11 - A Abr.1955 Vialidad según Planos Reguladores; 12 - B Abr.1955 Servicios Urbanos Electricidad; 13 C - May.1955 Servicios Urbanos - Electricidad; 14 - A May.1955 Servicios urbanos Teléfonos; 15 A - Jun.1955 Conjunto de P. Reguladores Comunales; 16 A - Jul.1955 Servicios Urbanos - Agua Potable; 18 A - Ago.1955 Equipamiento Urbano (Comercio, Cines); 19 A - Ago.1955 Equipamiento Urbano (Hospitales, Regimientos);20 A - Sep.1955 Equipamiento Urbano; 22 A May.1956 Servicios Urbanos - Electricidad y Gas; 23 A - Jun.1956 Curso Nocturno de Actividades; 24 A - Jun.1956 Equipamiento Urbano - Síntesis; 29 A - Nov.1956 Areas Verdes Existentes; 30 A Nov.1956 Densidad Nocturna - Censo 1952; 35 A - Ago.1957 Poblaciones Callampas; 38 A Sep.1957 Areas Construidas; 39 A - Nov.1957 Loteo y Extensión Urbana; 40 A - Nov.1957 Distribución de Población Censo Nocturno 1952; 41 A - Dic.1957 Expansión Urbana; 43 A - Ene.1958 Servicios Urbanos - Ext. Agua Potable y Alcantarillado; 45 A - Feb.1958 Límites Urbanos; 48 B May.1958 Catastro Industrial - Censo 1952; 50 A - May.1958 Aptitud de Suelos; 51 A - Jun.!958 Reducción de Límites; 53 F - Jul.1958 Aptitud de Suelos Actual; 54 F - Jul.1958 Aptitud de Suelos Potencial; 55 A - Ago.1958 Servicios Urbanos - Teléfonos; 58 D - Sep.1958 Comunas; 59 D Sep.1958 Agua Potable y Alcantarillado.
\end{abstract}

Cabe destacar el esfuerzo realizado para efectos de este expediente urbano toda vez que en los años 50 no se contaba con las innovaciones tecnológicas actuales (aerofotogrametría, fotos del satélite y otros).

La necesidad de realizar investigaciones multidisciplinarias globales previas a los proyectos de ordenamiento territorial debía atenderse con dedicación tal como lo hicieron Geddes, Munford, Auzelle, Bardet. Adicionalmente, Luis Muñoz ya en los años

32 CHILE - MINISTERIO DE OBRAS PUBLICAS, Dirección de Planeamiento, Departamento Planos Reguladores, "PLANO INTERCOMUNAL DE SANTIAGO", noviembre de 1958. Documento original MOP, carpeta ad hoc, conteniendo 11 páginas dactilografiadas sobre cartulina gris y 9 fotografías en color (formato carta aprox.) dispuestas en fundas plásticas, de los principales planos y proposiciones originales a escala 1:20.000, y 1:100.000. En Archivo de Juan Parrochia Beguin, 1990.

Revista de Urbanismo No6 - Julio de 2002 
1930 había propuesto en Chile, -y como una necesidad imperativa- la realización de "investigaciones científicas interdisciplinarias" en materia de Urbanismo.

\subsection{Sobre directrices de planeamiento e implementación día a día}

Auzelle y Bardet señalan que el Plan Director -que debe definir los principios generales que deben guiar el planeamiento del territorio- exigirá la comprensión del Plan como una creación incesante, continua, donde deben ejercerse en forma escalonada en el tiempo una larga serie de decisiones. Muchos otros deberán participar en las diversas escalas en que se fijará el detalle de las operaciones definitivas, dando cuenta de una gran diversidad creativa.

Al respecto, el Arqto. Juan Parrochia ha señalado insistentemente que los planes no son "de" un año determinado (aprobación), sino "desde" el año de su aprobación. La forma de su realización día a día, llevó a crear la "oficina del Plan". Esta última ya había sido sugerida por el Arqto. Luis Muñoz Maluschka en los años 1930.

La planificación chilena de los años 58/60, asumió el capítulo del Planeamiento de los espacios públicos, dejando el diseño de los polígonos o vías y diseño del entorno a otras instancias de realización y variados autores.

\subsection{Sobre diversificación de la oferta de espacios públicos}

Más allá de la nueva tipología de espacios verdes para recreación, de protección de recursos antes referida en detalle, y de tipos de industria y su adecuada localización que generaron los planificadores de los planes de 1960, cabe destacar que hay en estos planes una cierta oposición al modelo progresista de los CIAM, toda vez que se rechaza la estandarización de las respuestas a los problemas de las ciudades, optando por coordinar las necesidades de los habitantes, las exigencias del terreno y las condiciones climáticas, tal como lo había hecho Luis Muñoz en su momento.

Cabe destacar que Muñoz Maluschka vio, tempranamente, la necesidad de salir del esquema de las vías de perfil colonial, estableciendo vías mayores, donde realzaba las "vías de circunvalación urbana" en las grandes ciudades, para evitar la congestión en el centro de la ciudad. El mismo, había comenzado a construir un tramo de la circunvalación Américo Vespucio en Las Condes, que posteriormente los autores de los planes de 1960 redefinieron con un perfil de mayor dimensión.

Por otra parte, Luis Muñoz había advertido en los años 1930, la necesidad de establecer parcelaciones racionales en la ciudad, frente a las cuales la vialidad debía tener las dimensiones adecuadas. Más allá de esto, sus frecuentes citas a la 
Planificación urbana-regional y paisaje: impronta de los planes 1960-1994 para Santiago de Chile

planificación prusiana dieron cuenta de la voluntad de diversificar los cauces viales conforme se fuera desarrollando la entidad urbana ${ }^{33}$ :

"Se establecen directivas especiales, tanto para el tránsito caminero, estableciendo diversas categorías de las vías y su destino funcional, a saber, desde caminos de acarreo de productos agrícolas o mineros, hasta vías de tránsito liviano, pesado, a alta o baja velocidad, respectivamente, a larga o corta distancia; calles de diversas categorías de tránsito Hás. ta las calles residenciales de diferentes categorías".

\subsection{Sobre elevación de la densidad de población en medio urbano}

Los planes de 1960, propusieron elevar las densidades de Santiago, oponiéndose tal como hizo Munford, al despliegue de las urbanizaciones de baja densidad, por provocar estas, entre otros efectos negativos, la desintegración social y cívica.

Los planes debían responder a las necesidades masivas de recreación y también de civilidad: "El hombre es un animal político", había indicado además, Auzelle en una de sus críticas a Le Corbusier, dando cuenta de su interés en el desarrollo social de la civilidad.

Destacamos también en Luis Muñoz en 1936, las necesidades de ocupar adecuada y oportunamente los espacios eriazos al interior de las ciudades antes de crecer por extensión, por los costos que esto significa en redes y equipamientos y ocupación del suelo agrícola, y la necesidad de hacer un mejor aprovechamiento del suelo urbano disponible, elevando la altura de la edificación residencial y edificaciones en forma más continua, todo lo que, por cierto, tendría una repercusión en el paisaje cotidiano de los habitantes.

Para el cálculo de la densidad demográfica los planificadores de los planes de 1960 consideraron un 20 \% menos en el área urbana, a fin de dejar un margen para la futura oferta, variaciones de la demanda, u otras eventualidades.

Dicha superficie, sobre la base de una densidad de 144 habitantes por Há., permitiría una capacidad de 3.110 .000 habitantes. A ello se agregó una población suburbana, a partir de una densidad aproximada de 10 habitantes por Há., de 170.000 habitantes. El total urbano y suburbano sumó 3.280 .000 habitantes.

\footnotetext{
33 PAVEZ R. M. Isabel (compiladora), 1993, op.cit.

Adicionalmente, el mismo autor, más allá de promover las funciones ecológicas y recreativas de los espacios verdes, insiste en la necesidad de otros medios de "recreación y estímulo", toda vez que se refiere al deporte, el teatro, la lectura, la conferencia, los conciertos, las artes plásticas, teniendo al habitante no sólo como un espectador pasivo, sino como un intérprete, pudiendo desarrollarse el teatro obrero aficionado, asociaciones de música y canto, de gimnasia rítmica y otros. 
Suponiéndose una restructuración de la zona central sobre la base de remodelación y reconstrucción, en todas las comunas, se estimó un incremento de la densidad en un $52 \%$ lo que daría un valor de $220 \mathrm{Hab} . /$ Há. Luego, 21.600 Hás. (conteniendo el $20 \%$ de oferta libre), permiten con dicha densidad, 4.752.000 habitantes, a los que se agregan los 170.000 habitantes del área suburbana, totalizando 4.922.000 habitantes. Se pudo concluir que, según estas estimaciones, la capacidad urbana y suburbana podría llegar a un número de 5.000.000 de habitantes en 1990 .

\subsection{Sobre el espacio regional como un espacio de interés también paisajístico y disfrute colectivo}

Finalmente, en lo referido específicamente al paisaje, Munford promueve tomar efectiva "posesión del paisaje regional" para reestructurarlo en su conjunto. Promueve la creación de espacios de recreación abiertos, fuera de las áreas urbanas (parques paisajísticos, reservas naturales, y otros), desplegados por toda la región.

La nueva tarea del arquitecto paisajista debe consistir -señalaba- en estructurar el conjunto del paisaje de manera de integrar en él todos los elementos de un programa de recreación. Esto debe hacerse en la región sin perturbar las actividades económicas del campo (acceso público asociado a caminos turísticos, ciclovías, riveras de río, áreas de pic-nic, circuitos para visitas a granjas, etc.). En esta concepción no tiene cabida la realización de copias de "pueblitos", "aldeas" y otros al interior del área urbana.

El paisaje regional se concibe como un parque colectivo, con elementos diversos y desconcentrados de animación y recreación, que eviten la concentración masiva en un solo punto. Se da consideración mayor a los aspectos cualitativos de los espacios libres más que a sus dimensiones brutas.

Como ya vimos, esta concepción es explícita en el Plan de 1960 toda vez que despliega una gran diversidad de tipos de áreas verdes tanto en el área urbana como suburbana, y rural, aprovechando además, la naturaleza de la geografía de la región. Es claro también que -tal como Munford promueve- los planes de 1960 sobrepasan la sola función higiénica de los espacios públicos de recreación, para destacar también su función social.

Señaló el Arqto. Juan Parrochia, siendo estudiante, en una de sus memorias del ciclo de titulación, en $1952^{34}$ :

"El hombre es sólo una parte - y no un artífice- de la naturaleza, y sus esfuerzos de siglos para desligarse de ella lo han llevado a la desgracia y hacia su estrangulamiento paulatino mediante sus propias obras. El ambiente natural para el

\footnotetext{
${ }^{34}$ PARROCHIA BEGUIN, Juan, La naturaleza y una ciudad: Santiago de Chile, memoria de ejercicio, Taller Central, Prof. Arqto. Héctor Mardones Restat, Escuela de Arquitectura de la Universidad de Chile, 1952, original en archivo de J. Parrochia B. 2001.

Revista de Urbanismo Nº6 - Julio de 2002 


\section{REVSTA DE

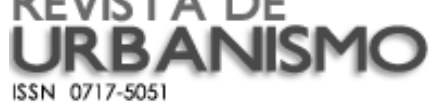

http://revistaurbanismo.uchile.cl

Planificación urbana-regional y paisaje: impronta de los planes 1960-1994 para Santiago de Chile

cual ha sido creado el ser humano debe devolverle su felicidad y su naturalidad. Es imprescindible que se restaure la naturaleza en las ciudades - y en los camposexponentes máximos del paisaje humano y artificial que las generaciones reciben como patrimonio obligado y que aceptan inconsciente y fatalmente, como si siempre hubiese sido así o debiese ser de esa manera. (...) la naturaleza debe ser el todo y la obra humana una parte de ella, y cuando esta domine a la primera habrá error. Cuando la bomba de hidrógeno sea más potente que las fuerzas que mantienen el equilibrio del mundo, este desaparecerá. La naturaleza no debe ser el decorado de la escultura, la arquitectura, la planificación, etc., sino que debe ser el conjunto en el cual estas actividades encuentren campo de expresión. (...) Santiago de Chile es el lugar de nuestro país donde el problema que hemos indicado se presenta con mayor nitidez y es donde encontramos grandes masas de población criminalmente alejadas de la naturaleza".

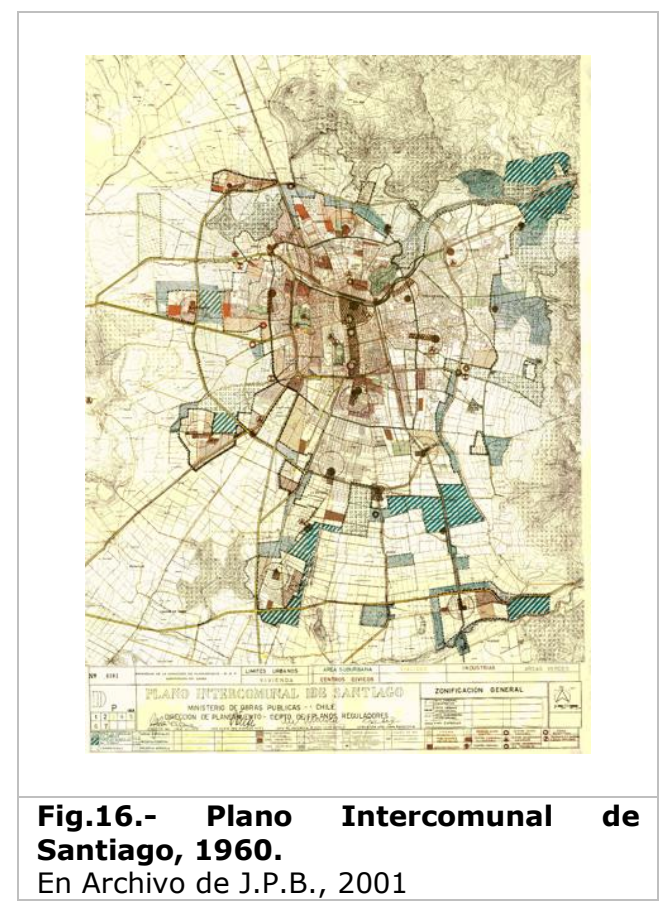

\section{Conclusión}

Concluimos en este escrito sobre espacio público y paisaje, que la confrontación de los datos compilados con las variables escogidas, nos permiten afirmar la validez de las hipótesis enunciadas al comienzo. 
En el paso de la ciudad tradicional y discreta de Santiago, a la metrópolis, los autores de los proyectos de planificación urbana y regional de 1958/60-1994 hicieron un esfuerzo evidente por aprovechar los múltiples valores de los recursos naturales del espacio habitable que intervinieron -entre ellos el paisajístico-, coordinándolos con sus proposiciones, y aplicando en ello los más relevantes conceptos recibidos de quienes fueron sus profesores y altos inspiradores.

Con sus proyectos señalaron oportunamente el camino hacia la sustentabilidad del desarrollo de los asentamientos humanos y abrieron por varias décadas, un amplio campo de trabajo a los profesionales chilenos de diversas disciplinas. Muchas de sus proposiciones de bien público mantienen su validez hasta el día de hoy, y permitirían sustentar proyectos urbanísticos en el siglo XXI. 